\title{
TMLAI Transactoons on

\section{On Comparative Study for Two Selective Ant Colony's Optimal Decisions Versus Reconstruction Problem Solving by a Mouse Inside Figure of Eight (8) Maze}

\author{
Hassan M. H. Mustafa, Fadhel Ben Tourkia \\ Computer Engineering Department, Al-Baha Private College of Sciences Al-Baha, \\ Kingdom of Saudi Arabia \\ prof.dr.hasssanmoustafa@gmail.com; bintorkih@yahoo.com
}

\begin{abstract}
This piece of research addresses an interdisciplinary comparative study of two environmental challenging phenomenal issues. Both were associated to two nonhuman creatures characterized by their behavioral intelligent performance concerned with optimal diverse decisions paradigms. More specifically, this paper deals with the comparison study for analogical behavioral learning of social insects (Ants) colony performance, versus performed behavioral learning achievement by an animal considering a mouse inside Figure of eight (8) maze via its brain hippocampus "time cells" neurons.

In more precise details, this paper firstly have demonstrated for Ant Colony System (ACS) the two effective optimal selectivity decisions for : a) The best source location between two food sources that are equidistantly sited away from the original home nest, based upon pheromone trails and following the tandem running regulation $\&$ b) The balanced selection performance with the migration speed, in order to minimize exposure to a hostile environment to avoid vulnerability to presumable danger. Secondly, the optimal decisional issue is demonstrated related to mouse's behavioral learning intelligent approach which observed in practice following its active sequential trials aiming to reach the optimal solution for a reconstruction problem during its movement inside figure of eight (8) maze. Finally, after running of realistic Artificial Neural Networks' (ANNS) simulation programs. Interestingly, the obtained results considering models of both of suggested intelligent behavioral learning issues characterized by relevant functional analogy considering changed number of artificial ant agents versus the various number of neurons inside mouse's hippocampus brain area.
\end{abstract}

Keywords- Artificial neural network modeling, Swarm Intelligence, Tandem Running, House-HuntingAnts, Nature Inspired Computing.

\section{Introduction}

The Ant is one type of social insects that have been evolved from wasp-like ancestors in the midCretaceous of the period between 110 and 130 million years ago [1]. It means they are as old as dinosaurs but unlike them, ants managed to survive. In more general sense, considering ants as social insects means they live in large colony systems or groups. In natural world, it is observable depending on the species, that ant colonies could be composed of millions ant members of (agents). [2] Accordingly, the colonies 
of ants (as a social insects), are behaving adaptively while living in a competitive, and dynamical environment. Which characterized by constantly changing food sources in their location (distributed sites), and variation of their quantity and quality. Most of ant species are dependent upon ephemeral food finds. In such an environment, there is an advantage to sharing information if it can help the colony direct its workers quickly to the best food sources. The second paradigm considers collective decisional intelligence as a behavior that emerges through the interaction and cooperation of large numbers of lesser intelligent agents (such as ants). This paradigm composed of two dominant sub-fields 1) Ant Colony Optimization that investigates probabilistic algorithms inspired by the foraging behavior of ants [3][4][5], and 2) Particle Swarm Optimization that investigates probabilistic algorithms inspired by the flocking and foraging behavior of birds and fish [6]. Like evolutionary computation, swarm intelligence-based techniques are considered adaptive strategies and are typically applied to search and optimization domains. That simulation the foraging behavioral intelligence of a swarm (ant) system used for reaching optimal solution of TSP a cooperative learning approach to the traveling salesman problem optimal solution of TSP considered using realistic simulation of Non-neural systems namely: Ant Colony System ACS. In the context of intercommunications and cooperative learning among ants inside ACS. More specifically, Social insects have evolved impressively sophisticated solutions to some challenging environmental issues such as making nest site selection via building a leading model system of the collective intelligence of animal insect groups Temnothorax ants. Recently, educationalists have adopted interesting interdisciplinary challenging research work concerned with realistic modeling behavioral learning of some behavioral nonhuman creatures compared with ACS intelligent performance [7]. That's seems to be analogous to the natural aspects of behavioral ecological learning (swarm intelligence), observed by one type of social insects colonies namely (ACS) [6]. By referring to [6], therein has been interestingly stated that: " How do ants communicate so quickly and clearly? The German ethologist and socio biologist Prof. Bert Hölldobler researches in this field for many years. Together with the American Edward $\mathrm{O}$. Wilson, he has revolutionized the study of ants. He says: An ant colony functions like a super organism. The life of each single being counts for little, the survival of the super organism, the state, is all what counts". Moreover, it has been announced, at[6] some of interesting findings associated to "Ants Beautiful Creation of Allah", by following words "This particular insect has been selected as a title (Aayat) of a Surah No.27 "The Ants" in the Noble Qur'an. Briefly, it discusses the advent of Hadhrat Sulayman (Alayhis salaam), with his hosts of Jinn, men and birds and they marched in arranged groups till they reached the Valley of Ants. Said one Ant "Oh you Ants! Get back into your dwellings, lest Sulayman and his hosts crush you unintentionally". The Hadith and sayings of the companions are numerous relating to the Ant. Hadhrat Ibn Abbas (Radhiallaahu Anhu) reports that the Prophet (Pbuh) said, "Do not kill four of these creatures viz. ant, bee, sparrows (wood-pecker), and any pigeon". Hadhrat Abdur Rahman Ibn Abdullah (Radhiallaahu Anhu) reports that The Prophet (Pbuh) descended at a certain place - (house) and attended to the call of nature. Incidentally a man kindled a fire in a heap of ants, (either the house was built on a tree or on the ground). The Prophet (Pbuh) seeing this, exclaimed "Who did this? Extinguish it!! Extinguish it!" Abu Hurayrah (Radhiallaahu Anhu) reports that a certain Prophet from the many Prophets (Alayhis salaam) rested under the shade of a tree. An ant bit him. So the Prophet stood up to avenge for the bite. He spotted a large group of ants and killed them. A call was voiced to Him, "Was it not only one ant that bit you?" Abu Hurayrah (Radhiallaahu Anhu) reports, I heard the Prophet (Pbuh) saying, A certain Prophet from the many Prophets (Alayhis salaam) was resting under the shade of a tree. An ant bit him. He instructed his belongings to be removed from there and immediately ordered the heap of Ants to be 
Hassan M. H. Mustafa, Fadhel Ben Tourkia; On Comparative Study for Two Selective Ant Colony's Optimal Decisions Versus Reconstruction Problem Solving by a Mouse Inside Figure of Eight (8) Maze. Transactions on Machine Learning and Artificial I ntelligence, Volume 6 No 3 June (2018); pp: 1-19

burnt. Allah Ta'ala revealed to him "Was it not only Ant that hurt you and you have ordered a full nation of ants to be destroyed who are engaged in the invocation of Allah Taala? Was it not one ant?" Hassam Dastawani says that the ants and small ants during the season of summer bring love and prosperity to us but during the season of winter we fear they will dissipate our hoards. Abu Bakr Najee reports that Hazrat Sulayman (Alayhis salaam) came out seeking water. Incidentally he spotted an ant with its bottom downwards and struggling with its legs up in the air upwards and saying, "Oh Allah we are one of your own creation, we are not independent of our thirst. Either you refreshen us and feed us or either kill us and destroy us." When they reached the Valley of the Ants, an Ant exclaimed, 'O Ants! Enter your dwellings lest Sulaymaan and his armies crush you without noticing it." [Qurán 27:18) Life Style of Ants In recent times, research has shown us several facts about the lifestyle of ants, which were not known earlier to mankind. Research has shown that the animals or insects whose lifestyle is closest in resemblance of the lifestyle of human beings are the ants. This can be seen from the following findings regarding ants:

a. The ants bury their dead in a manner similar to the humans.

b. They have a sophisticated system of division of labour.

c. Once in a while they meet among themselves to have a 'chat'.

d. They have an advanced method of communication among themselves.

e. They hold regular markets wherein they exchange goods.

f. They store grains for long periods in winter and if the grain begins to bud, they cut the roots, If the grains stored by them get wet due to rains, they take these grains out into the sunlight to dry, and once these are dry, they take them back inside.

By more precise details for quantitative evaluation of number of processing elements (Ant agents) versus human brain neuronal cells. And by referring to the investigational analysis of observed cooperative behavioral social insects intelligent learning phenomenon among ants at ACS. The analogical comparative study of ants at ACS versus human brain's intelligence is performed by contributing group of neuronal cells inside the brain. This comparison characterized by its interdisciplinary, and challenging educational issue resulting in the very interesting quantitative findings briefly presented as follows. The experts estimate that an ant brain contains about 250,000 brain cells [7]. That number pales in comparison to the human brain, which is believed to contain over 86 billion neurons. However, for the ant, its brain is quite powerful. A human brain has about 10,000 million so a colony of 40,000 ants has collectively the same size brain as a human. However, in natural real world, some of ant colonies may be composed of millions of ant agents (members) [1]. Furthermore, by referring to [8], therein announced in words that : " of all the insects in the world, the ant can claim to have the largest brain". In fact, some scientists believe the ant has the largest brain in proportion to its size of any creature on Earth!." Accordingly, Ants are widely considered to be the smartest insect in the world [7]. Moreover, in the analogical context of bidirectional interactive human's educational process in classrooms versus ACS performance. Scientists have announced the finding that ants observed to be the first example of nonhuman animal that are capable of performing two-ways interactive instruction.[9].

This interdisciplinary research article motivated by Ant Colony's behavioral observations for two optimal selective cooperative decisions made by all of colony's ant-mates. Firstly, the decision related to 
considering optimal selectivity problem between two food sources, one of them contains higher sugar amount than the other source. Both sources are simultaneously sited equidistant away from the original nest' colony site [10]. Herein, the analysis and evaluation of the two adopted modeling problems presented considered to be involved by self-organized mechanism. That's pointing out to perform optimal convergence of tandem running process directing towards the either better source with trailing marked by higher pheromone (for the first problem). Or directing the way to -even distant best nest site (for the second problem). In more details, the ants recruited as foragers visited the source containing higher amount of sugar which marked by the trailing pheromone resulting in directing towards the source with greater sugar amounts rather than visiting the source with lower in sugar [10]. Secondly, on the other hand, ACS performed optimal selectivity decision for finding (best) sheltered nest. That is by following stimulation of released a pheromone from her mandibular gland to avoid its vulnerability to presumable danger. Interestingly, it is noticed that selectivity case is greatly similar to optimal selection process of food source. This problem is following the tandem running regulation helping to carry over directions to new nests. That in accordance with what has been announced by O'Shea-Wheller [11]: "Colonies counteract the difficulty of finding a distant nest, simply by increasing the rate at which individuals give each other 'directions'". And thus, the amount of directional information that a colony gathers increases as a function of migration distance, sort of like a self-organizing route planner". Specifically, the two problematic issues achieve optimality of decisions by modulating the rate of 'tandem running', in which ants workers teach each other the route to either a better food source or a new nest site. In brief, both of the suggested problems are autonomously (Self-organizing) perform selective searching considering speed-accuracy trade off for optimum decision to reach either best source or nest site. Recently, three research papers have been published which concerned with comparative analogical study for both above problems originated from ants' swarm intelligence after application of Tandem Running Technique, which published at [12][13][14].

Herein, the intelligent behavioral performance of the second nonhuman animal (mouse), is demonstrated. Noticed the number of neuronal cells functioned as place field cells (at hippocampus mouse's brain area). That number is in well correspondence with the number of ant agents recruited for either ACS decision makers in the above [10][11]. More precisely, the contribution of neurons as place field cells at the mouse's hippocampus area resulted in minimum value of error by reaching (Cramer-Rao limit), while solving reconstruction problem [15][16][17][18]. Recent studies on the hippocampus have led to a new model of how the hippocampus forms and replays memories and so, the mouse had to run back and forth through the maze, from left to center to right, back to center, then left, and so on. The critical choice point was as the mouse left the center arm and had to remember whether it had most recently come from the left or right arm and choose the alternate direction [19][20][21]. Therefore, both introduced issues given at this paper's abstract, seem to be tightly related to the interactive learning responses of the two suggested types of nonhuman creatures (Ant \& Mouse) with the natural environment they are living in [22].

At [12], the paper dealt with the Comparison for the performance of some Behavioral Learning system models versus of an Ant Colony Optimization performance. The comparison between the above two problems originated from ants' swarm intelligence behavioral performance after application of Tandem Running Technique, is presented at [13]. The rest of this paper is organized in five sections, in addition to the above previous first introductory section. These sections are briefly given as follows. The second next 
Hassan M. H. Mustafa, Fadhel Ben Tourkia; On Comparative Study for Two Selective Ant Colony's Optimal Decisions Versus Reconstruction Problem Solving by a Mouse Inside Figure of Eight (8) Maze. Transactions on Machine Learning and Artificial I ntelligence, Volume 6 No 3 June (2018); pp: 1-19

section presents revising of the selectivity decisional process of an optimal (best) food source. A review of ant colony migration strategies from the home nest to another non-vulnerable one to any potential danger is given at the fourth section. At the fourth section, analysis of reconstruction problem solution by a mouse inside Figure eight (8) maze is presented. The obtained simulation results are given at the fifth section. Finally, some interesting conclusive remarks are introduced at the last sixth section.

\section{Ant's Selection of Best Food Source}

\subsection{Selection Between Two Pawthays Using Pheromones' Marking}

If an experimenter offers a colony of mass recruiting ants, one of the species using pheromones to food trails, two food sources simultaneously and at equal distances from the nest, but one is higher in sugar content than the other, most of the foragers will usually go to the source higher in sugar. Some of the foragers will feed from the source lower in sugar, but on the average, their numbers will be much lower than those going to the better source. This is of course a good decision for the survival and reproduction of the colony: the ants concentrate on the food source that provides the most calories with the least amount of effort. But how do they do this? How do they "decide" which source is better and how do they coordinate their efforts so as to exploit it preferentially?.[10]. Herein, a proposed explanation is currently introduced for how towards the better source containing the greatest amounts of pheromone and differentially choose these trails over those to lesser sources marked with smaller amounts of pheromone, illustration of how a group of ants able to optimally decide the selectivity of a shorter path to reach the food source via an asymmetrical simplified bifurcations network (referring to Fig.1.).

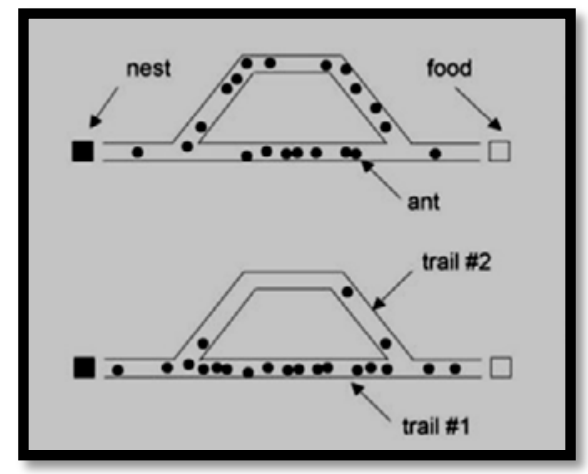

Figure 1 Schematic illustration of the ant algorithm. (At the top). Selection of a shorter path between a nest and a food source by natural ants. The ants travel between the nest and food through trail \#1 and trail \#2. Initially, ants are distributed equally on both trails . (At the bottom). Since trail \#1 is shorter than trail \#2, trail \#1 becomes their favorite pathway with a higher pheromone concentration. (Adapted from[23])

\subsection{Selection of Minimum Pathway Between Source and Nest}

Referring to Fig.2, in the case of bifurcation occurrence due to an existence of an obstacle at some point placed on the pathway between the nest site and that of the source, the transportation process of food (from food source) to food store (nest). is illustrated behavioral ants' responses shown at the simplified sketched figure considering the pheromone trail between nest and food source. 


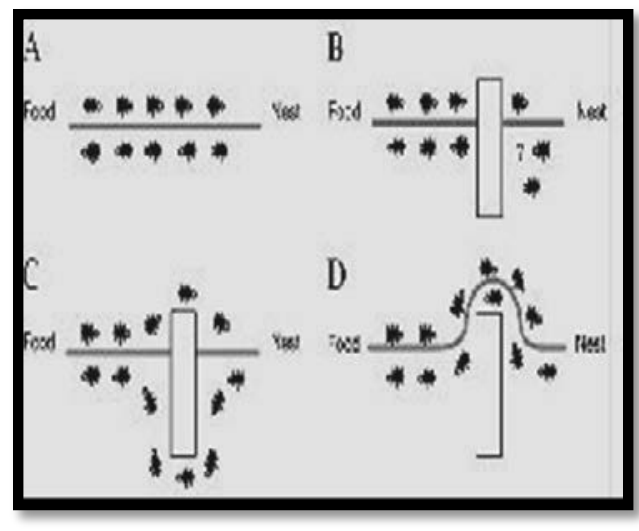

Figure 2. Ant Behavior A. Ants in a pheromone trail between nest and food; B. An obstacle interrupts the trail; C. Ants find two paths to go around the obstacle; D. A new pheromone trail is formed along the shorter path.

Accordingly, the persistent or recurring food sources may also be available, such as the aphids or scale insects 'farmed' by many ant species. The best strategy is often to remember rewarding foraging sites but also to be flexible enough to exploit newly discovered food and to select the better sources from those available. To this end, information directing nest mates to food also enables them to select the highest quality food find when multiple resources are available [10].

\subsection{Selection of one Path Between Two Diamond's Branches}

Referring to [24], it is announced that, one of the most striking features of an ant colony's behavior is its capacity for the spatial organization of foraging activity. The use of trail pheromone to guide fellow workers in the nest to a large food source or rich foraging zone has been extensively studied [25] and obviously contributes to foraging efficiency. We have recently, however, been able to show that trail laying and trail following behavior are more than just a means of communicating a food source's location. When more than one trail is present at a time, the interactions between foragers and the trails can lead to the collective selection of the shortest path or the best food source, despite the fact that individual foragers have no means of making such choices. Referring to the published research work at [26], it reveals the importance of the shape of trail networks for foraging in ants and emphasizes the underestimated role of the geometrical properties of transportation networks in general. 


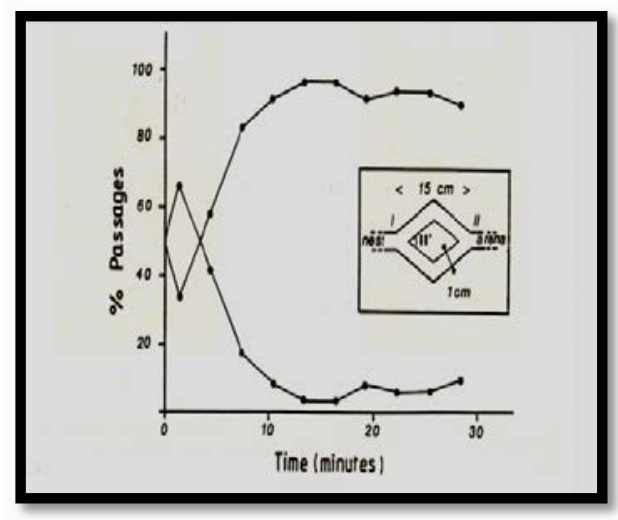

Figure 3. Percentage of the ant workers per three minutes period that are passing on the two branches of the diamond bridge (Adapted from [27])

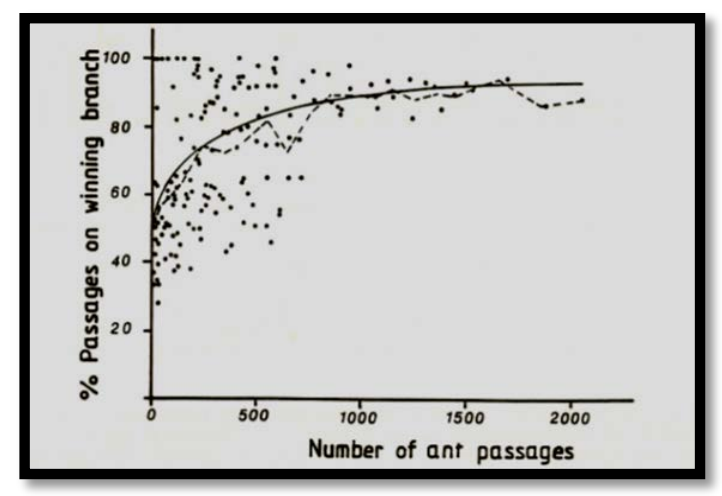

Figure 4. Percentage of the ant workers that are passing on the collectivity selected winning branch of the diamond bridge (shown at Fig.3) resulting after 20 experiments measured every three minutes(dotes). Noting that horizontal axis represents the cumulative number of ant passages on both branches of the diamond bridge. The dashed curve represents the average values. The solid curve represents the average of $\mathbf{2 0 0}$ monte-Carlo Simulations.(Adapted from[24]).

\section{Organization of Colony Migration}

This section composed of three subsections which concerned with recruitment of signals used by successful foragers or nest site scouts, but another fundamental type of communication is alarm signaling. In social insects [28], defensive behavior is closely connected with alarm signals that either recruit nest mates to combat a potential-danger or warn them to stay away [29][30][31].

\subsection{A. Application of Tandem Running Approach for performing ACS Emigration Function}

By referring to [32], detailed of the emigration functions is organized by a minority of active scouts, roughly one-third of the colony's workers. Each of these scouts sets out from the damaged nest to find a new home, thoroughly inspecting any candidate that she finds. If it passes muster, she returns to the old nest to reaching the site, but even these broken tandems recruit ants, because the orphaned follower enjoys a higher chance than a naive searcher of finding the target. Tandem followers make their own assessment of the site and may also begin to recruit. The resulting positive feedback increases the site's population, until it reaches a critical level and triggers a dramatic change in behavior She uses a behavior called tandem running, in which she attracts a single recruit to follow her toward the new site as shown at Figure 5. Their progress is slow and halting, as the leader must pause frequently to allow her follower to catch up. The pair often lose contact for good before reaching the site, but even these broken tandems recruit ants, because the orphaned follower enjoys a higher chance than a naive searcher of finding the target. Tandem followers make their own assessment of the site and may also begin to recruit. The resulting positive feedback increases the site's population until it reaches a critical level and triggers a dramatic change in behavior. Scouts cease tandem runs from the old nest, and instead begin to carry nest mates, one at a time, to the new site Figure 6 . Scouts cease tandem runs from the old nest, and instead begin to 
carry nest mates, one at a time, to the new site. These transports are roughly three times faster than tandem runs, and population growth accelerates sharply. Over the next few hours, the entire colony is brought to its new home. inform other scouts of its location.

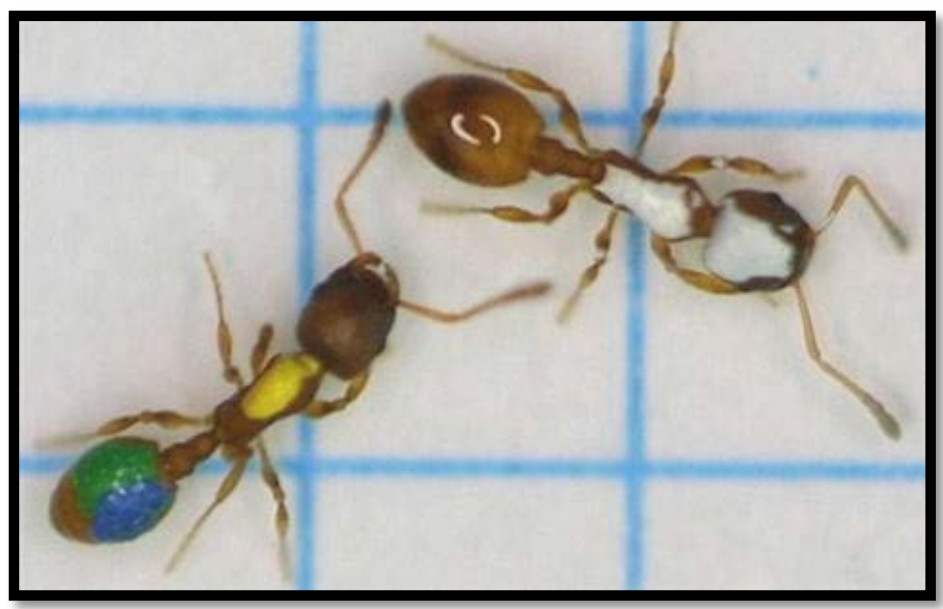

Figure 5. Worker ants teach others the way to food with a poking and prodding technique called "tandem running." These ants have been daubed with paint for tracking purposes. Additionally, by adopting tandem running, a single ant is slowly led to a candidate site performing the migratory behavior forms an intrinsic part of the life histories the house hunting ant Temnothorax albipennis. colonies. [Adapted from [32] and image from Nigel Franks and Tom Richardson / University of Bristol]

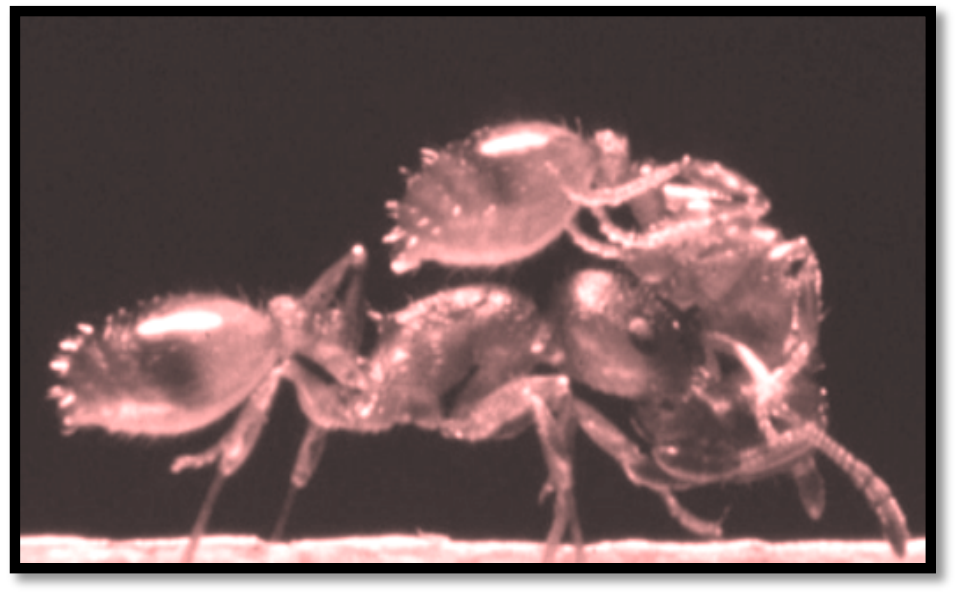

Figure. 6. Recruitment behavior used in emigration by Temnothorax albipennis colonies. Social transport, in which a single nest mate is rapidly carried to the new site. (Adapted from [32])

\subsection{Selection Between Two Target Nests}

Referring to [28], the migratory behavior forms an intrinsic part of the life histories of many organisms but is often a high-risk process. Consequently, varied strategies have evolved to negate such risks, but empirical data relating to their functioning are limited. In this study, we use the model system of the house hunting ant Temnothorax albipennis to demonstrate a key strategy that can shorten migration exposure times in a group of social insects. Colonies of these ants frequently migrate to new nest sites, and due to the nature of their habitat, the distances over which they do so are variable, leading to fluctuating potential costs dependent on migration parameters. Regarding to the closest resemblance of ants' lifestyle with respect to that of human beings. local advanced intercommunication observed via chatting 
Hassan M. H. Mustafa, Fadhel Ben Tourkia; On Comparative Study for Two Selective Ant Colony's Optimal Decisions Versus Reconstruction Problem Solving by a Mouse Inside Figure of Eight (8) Maze. Transactions on Machine Learning and Artificial I ntelligence, Volume 6 No 3 June (2018); pp: 1-19

signaling among colonies' agents (ants). These signaling findings have been basically originated in accordance with the intercommunicative distributed collective cognition decisions among ants' colony members. Specifically, in the case of anticipated danger analysis, evaluation and deciphering of emerged alarm communication signals against predators resulting in variety of behavioral responses. In more details, considering the colony of Temnothorax rugatulus, it has been reported that alarm signaling pheromone while electing two different behaviors is dependable upon different context.

\subsection{Binary Choice Between Two Nests [28]}

Referring to Fig.5, When an ant was tethered inside an unfamiliar nest site and unable to move freely, she released a pheromone from her mandibular gland that signaled other ants to reject this nest as a potential new home, presumably to avoid potential danger. Accordingly, it is clearly possible that this pheromone's function can improve an emigrating behavioral response for colony's nest site selection performance. Colonies were given a binary choice between a nest with tethered ants and a nest that had five strings but no ants. By referring to Figure 7, concerned with test arena, were given a binary choice between a nest with tethered ants and a nest that had five strings but no ants. These two target nests were first placed adjacent to one another against one wall of the test arena. The home nest containing the colony from which the tethered ants were taken was then placed against the center of the wall opposite to the location of the target nests. Finally, the roof of the home nest was removed to induce migration.

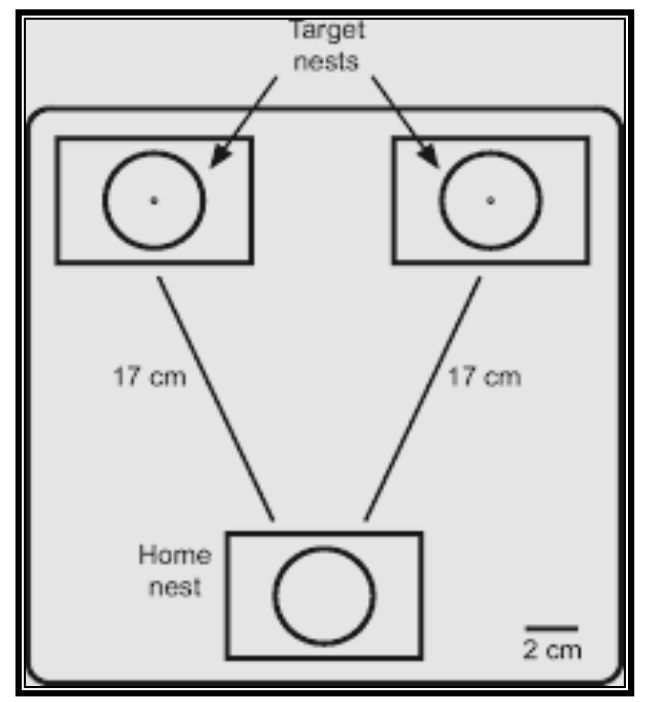

Figure 7. Experimental arena for nest choice tests. Colonies initially lived in the home nest, from which the roof was removed to induce migration. Colonies were allowed to choose between two target nests, which were identical in design but contained different materials (see Materials and methods for details). The arena size was $20 \times 20 \mathrm{~cm}$ and $1 \mathrm{~cm}$ in height. (Adapted from [28]).

\section{Reconstruction Problem Solving by a Mouse}

\subsection{Function of Brain's Hippocumpus Area [16]}

Hippocampus is said to be involved in "navigation" and "memory" as if these were distinct functions. In this issue of Neuron [17]. It provides evidence that the hippocampus retrieves spatial sequences in support of memory, strengthening a convergence between the two perspectives on hippocampal function. The following four interesting findings presemting basic characterisics aspects of the Brain's 
Hippocumpus Area, that obtained after a set of distict research works published recently to support investigational research inside Fig. 8 maze, aiming to shed light on the function of brain 's hippocampus Area:

a) Referring to [21], experimental testing performed for hippocampus brain area observed neural activity results in very interesting findings. Therein, ensemble recordings of 73 to 148 mouse's hippocampal neurons were used to predict accurately the animals' movement through their environment, which confirms that the hippocampus transmits an ensemble code for location. In a novel space, the ensemble code was initially less robust but improved rapidly with exploration. During this period, the activity of many inhibitory cells was suppressed, which suggests that new spatial information creates conditions in the hippocampal circuitry that are conducive to the synaptic modification presumed to be involved in learning. Development of a new population code for a novel environment did not substantially alter the code for a familiar one, which suggests that the interference between the two spatial representations was very small. The parallel recording methods outlined here make possible the study of the dynamics of neuronal interactions during unique behavioral events.

b) The hippocampus is said to be involved in "navigation" and "memory" as if these were distinct functions [17]. In this issue of Neuron this research paper evidence has been provided that the hippocampus retrieves spatial sequences in support of memory, strengthening a convergence between the two perspectives on hippocampal function.

c) Recent studies have reported the existence of hippocampal "time cells," neurons that fire at particular moments during periods when behavior and location are relatively constant as introduced at [18]. However, an alternative explanation of apparent time coding is that hippocampal neurons "path integrate" to encode the distance an animal has traveled. Here, we examined hippocampal neuronal firing patterns as rats ran in place on a treadmill, thus "clamping" behavior and location, while we varied the treadmill speed to distinguish time elapsed from distance traveled. Hippocampal neurons were strongly influenced by time and distance, and less so by minor variations in location. Furthermore, the activity of different neurons reflected integration over time and distance to varying extents, with most neurons strongly influenced by both factors and some significantly influenced by only time or distance. Thus, hippocampal neuronal networks captured both the organization of time and distance in a situation where these dimensions dominated an ongoing experience as illustrated at Figure 8. in below. [18].

d) Referring to Figure 9., to receive reward at the ends of maze arms, the rat had to run back and forth through the maze, from left to center to right, back to center, then left, and so on. The critical choice point was as the rat left the center arm and had to remember whether it had most recently come from the left or right arm and choose the alternate direction. The main finding in this study is that, as animals approached the critical choice point, the amount of hippocampual replay of both left and right routes predicted accurate choices. The optimal selected right choice is obtained in accordance with the stored experience at synaptic connectivity after its interaction with its environment [19][22]. Therefore, the observed optimal selective moving direction of the mouse is reached as a spontaneous response towards being inside Figure-of-eight-(8)maze. 


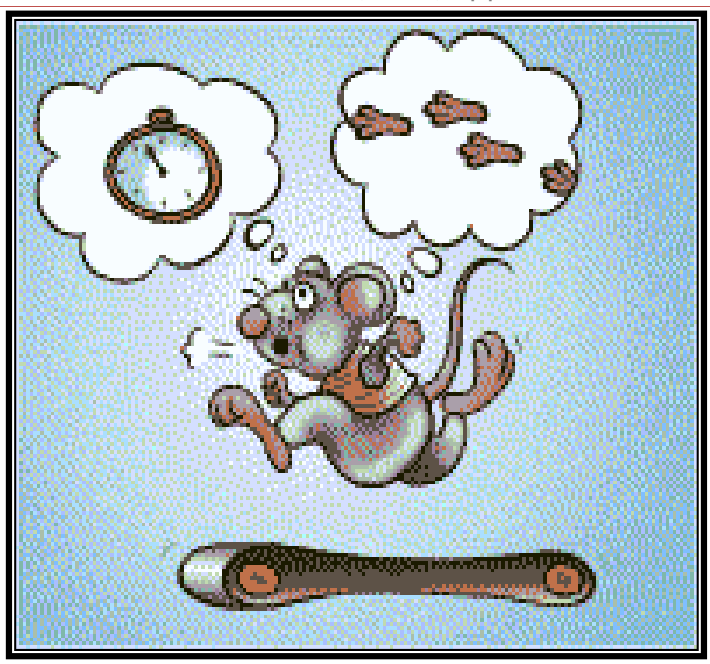

Figure 8. Dissociation between elapsed time and path integration in the hippocampus during the delay period of a working memory task required the mouse to run on a treadmill for either a fixed amount, (Adapted from [18]).

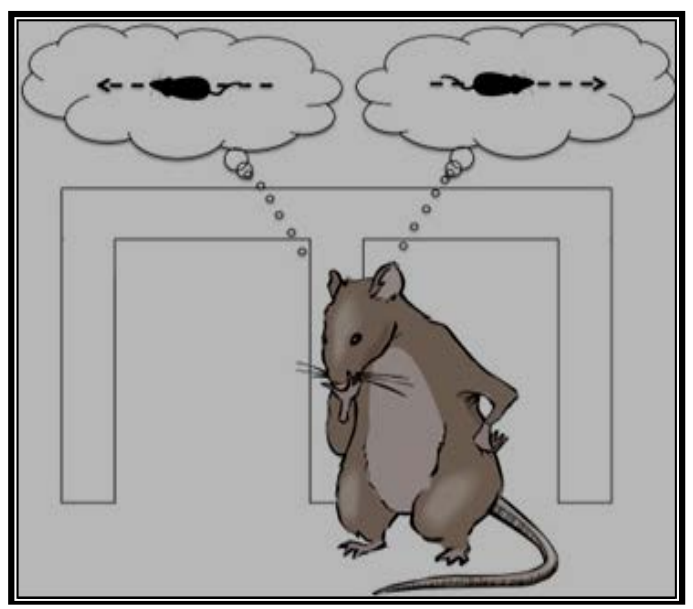

Figure 9. Retrieving memories of mouse's making decisions to select the correct direction in accordance with the stored experience at synaptic connectivity pattern of mouse's hippocampus area. (Adapted from [19]).

\subsection{Maze Reconstruction Problem}

Referring to measured mean error results shown at Table1, for solving reconstruction (pattern recognition) problem by a mouse inside a figure of eight (8) maze [15][16][20]That solution is carried out in accordance with the sliding of time window forward, the entire time course of $x$ can be reconstructed from the time varying-activity of the neural population. Furthermore, that table is graphically represented as the algorithmic performance learning curve referred to Figure 11. It is noticed that decreasing of the mean error values is similar as an exponentially decayed function converged to some limit value versus (place field) cells. That converged limit (by the increased number of cells) reaches some value, named as Crammer-Rao bound. Originally that limiting bound is deduced from Fisher's information given in tabulated results (Table.1), obtained after an experiment for trials to solve reconstruction process from a pattern recognition problem [15]. Interestingly, the effect of increasing number of place field neurons in rat's brain hippocampus is analogous to the increased iterative training trials observed by the behavioral performance of some other nonhuman animals such as dogs and cats. These behaviors observed as results of performed Pavlov's and Thorndike's psycho-experimental works 
respectively.[33][34][35][36][37], in addition to the introduced comparative analogy of quantified learning creativity in humans versus behavioral learning performance in animals: Cats, Dogs, Ants, and Mice [38].

Table 1 Relation between Number of Cells and Mean Error in Solving Reconstruction Problem

\begin{tabular}{|c|c|c|c|c|c|c|}
\hline \# neuron cells & 10 & 14 & 18 & 22 & 26 & 30 \\
\hline Mean error $(\mathrm{cm})$ & 9 & 6.6 & 5.4 & 5 & 4.5 & 4 \\
\hline
\end{tabular}

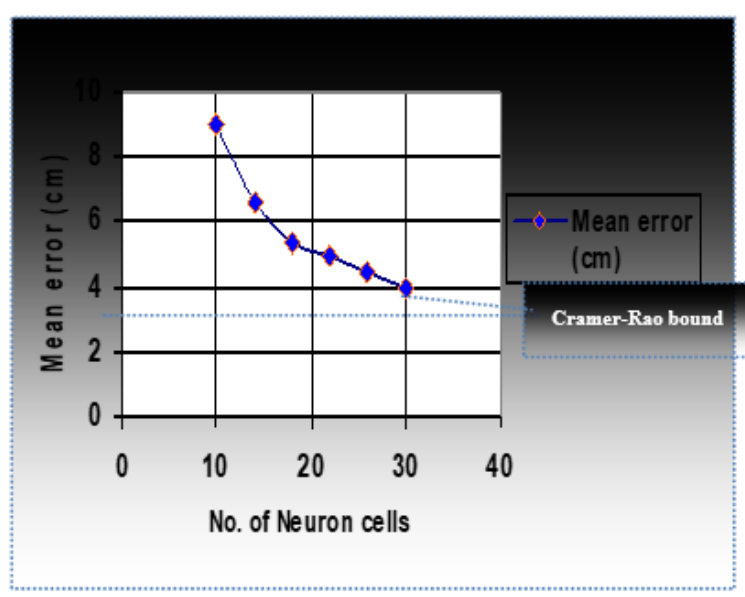

Figure 10..The dashed line indicates the approach to Cramer-Rao bound based on Fisher information adapted from [15]

\section{Simulation Results}

The presented simulation results have been in agreement with and supported by some obtained realistic computer modeling results, and announced findings published at a set of pieces of research manuscripts $[39],[40],[41],[42],[43],[44]$, and [45]. Referring to Figure 4., the performance of an Ant Colony via the winning branch reaches some percentage value [\%] after passing collectively a group of ant workers. This performance is dependable upon individual differences of ant colonies. This differences are simulated by Fig.9 while reaching the solution of Travelling Salesman Problem with different values of intercommunication parameters among ant colony agents. Referring to Fig.10, the different learning rate values $\eta=0.05,0.1$, and 0.2 are analogous to different intercommunication values among ant agents. That is by considering self-organized responses. resulted in convergence to different relative error values e(n) percentage values [\%], after any fixed time period \{number of trials (n)\}. Moreover, the three curves at Fig.11, are analogous to the results shown at Fig.4. Referring to Fig.12, it simulates the performance of mouse's convergence to bounding limit (of minimum error value) fixed Cramer Rao bound (Limiting value) at Fig.8. Moreover, Fig.12, simulates the individual difference performance of animals as that illustrated recently at [16], where the neuronal population activity is evaluated during solving of reconstruction problem inside Fig.(8) maze via application of hippocampus place cells. 
Average Speed to

Optimum Solution (1Sec.)

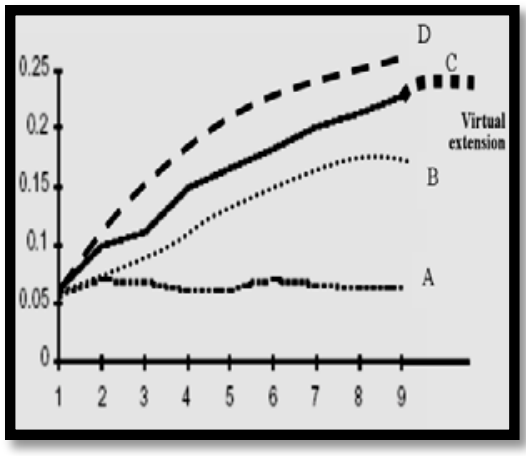

Number of Ants

Figure 11.. Communication determines a synergistic effect with different inter communication

levels among agents leads to different values of average speed

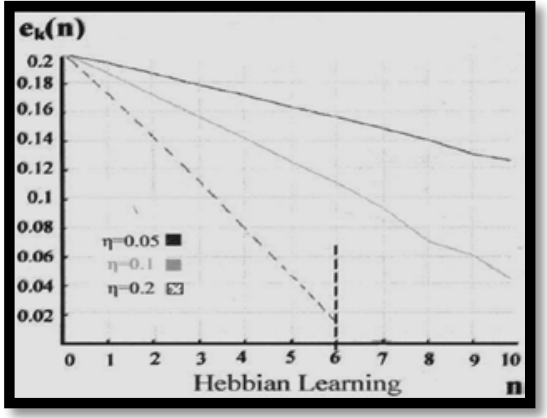

Figure 12. Adaptability performance concerned with self-organized Hebbian learning algorithm with learning rates $(0.05,0.1,0.2)$. (Adapted from[46]).

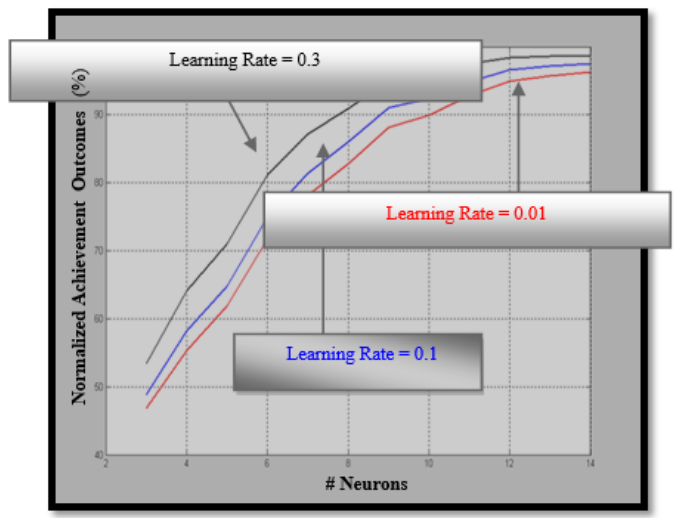

Figure 13. Illustrated the simulated output results presented as percentage degree[\%] of normalized achievement outcomes versus \# Neurons for different learning rate values $\eta(0.01,0.1$,and 0.3$)$. and constant gain factor $=1$

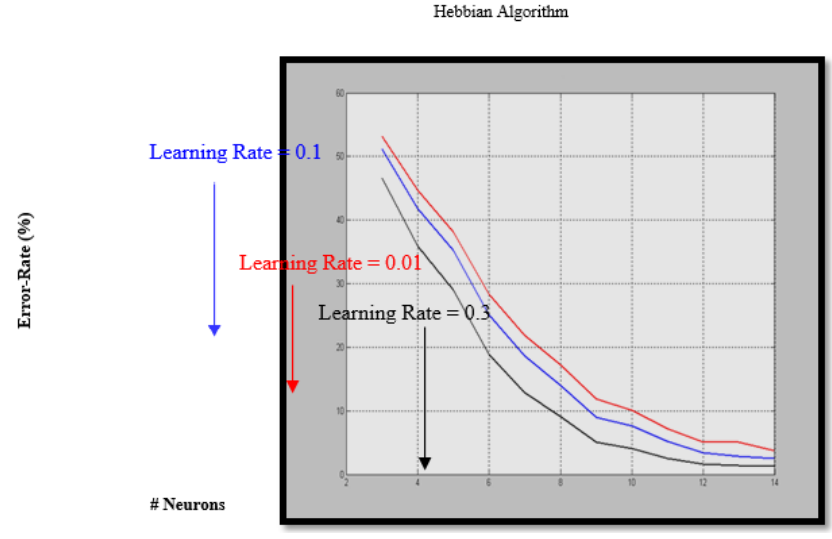


Figure 14. Illustrate learning performance error-rate with different learning rate values $\eta(0.01,0.1$, and 0.3). when \#cycles $=\mathbf{3 0 0}$ and gain factor $=\mathbf{1}$.

\section{Conclusions}

This piece of research comes to four interesting conclusive remarks presented as follows:

- The existence of an obstacle at some point of ants' pathway (Figure 2), results in various trailing pheromone tracing. Due to asymmetry of obstacles' shape, the time needed to find the shorter pathway is directly proportional to the discovery of the minimum path.

- Ant colony optimization algorithms have been applied to many combinatorial optimization problems, ranging from quadratic assignment to fold protein or routing vehicles and a lot of derived methods have been adapted to dynamic problems in real variables, stochastic problems, multi-targets and parallel implementations. It has also been used to produce near-optimal solutions to the travelling salesman problem.

- The humble ant is not only capable of solving difficult mathematical problems, but is even able to do what few computer algorithms can - adapt the optimal solution to fit a changing problem, deepen our understanding of how even simple animals can overcome complex and dynamic problems in nature, and will help computer scientists develop even better software to solve logistical problems and maximize efficiency in many human industries.

\section{REFERENCE}

[1]. $\quad$ Ted R. Schultz " In search of ant ancestors Proc Natl Acad Sci U S A. 2000 Dec 19; 97(26): 14028-14029. Published online 2000 Dec 5 at: https://www.ncbi.nlm.nih.gov/pmc/articles/PMC34089/ doi: 10.1073/pnas.011513798

[2]. "Ants: Fun Facts about Ants \& Ant Information for Kids - Pest World for Kids". Available online at: https://pestworldforkids.org/pest-guide/ants/

[3]. E. Bonabeau, M. Dorigo, and G. Theraulaz. Swarm Intelligence: From Natural to Artificial Systems. Oxford University Press US,999.

[4]. M. Dorigo and T. St?utzle. Ant Colony Optimization. MIT Press,2004.

[5]. J. Kennedy, R. C. Eberhart, and Y. Shi. Swarm Intelligence. Morgan Kaufmann, 2001.

[6]. How ants communicate? Available on line at http://www.youtube.com/watch?v=gcHt5n3NGK0 Uploaded on Jul 28, 2011.

[7]. Seid, M. A.; Castillo, A.; Wcislo, W. T. (2011). "The Allometry of Brain Miniaturization in Ants". Brain, Behavior and Evolution. 77 (1): 5-13. Available online at: https://www.karger.com/Article/Abstract/322530.

[8]. John, and Sarah "Interesting Facts About Ants" Published at Free Materials (C) 1996. Available online at: http://www.lingolex.com/jstefl.htm 
Hassan M. H. Mustafa, Fadhel Ben Tourkia; On Comparative Study for Two Selective Ant Colony's Optimal Decisions Versus Reconstruction Problem Solving by a Mouse Inside Figure of Eight (8) Maze. Transactions on Machine Learning and Artificial I ntelligence, Volume 6 No 3 June (2018); pp: 1-19

[9]. Bjorn Carey "Ants help each other as teachers and pupils" Available Online by date Jan 11, 2006 at: http://www.nbcnews.com/id/10806078/ns/technology_and_science-science/t/ants-help-each-otherteachers-pupils/\#.Ws5hLS5ublU , (c) 2012 Live Science.com. All rights reserved.

[10]. Ivan D. Chase, Abhijit V. Deshmukh \& Naga Krothapalli:" How do Ants Decide Between Food Sources of Different Values? An evaluation of the Current Explanation and Associated Mathematical Models" Published at the PROCEEDINGS of the 2nd International Workshop on the Mathematics and Algorithms of Social Insects Georgia Institute of Technology, Atlanta, GA.30332, December 15-17, 2003, pp. 41-46.

[11]. O'Shea-Wheller, T. A. et al. (2016). Migration control: a distance compensation strategy in ants, The Science of Nature, DOI 10.1007/s00114-016-1386.

[12]. Hassan M. H. Mustafa, Fadhel Ben Tourkia, Ramadan Mohamed Ramadan"On Analysis and Evaluation of Comparative Performance for Selected Behavioral Neural Learning Models versus One Bio-Inspired NonNeural Clever Model (Neural Networks Approach) Open Access Library Journal, Vol.3 No.10, October 31, 2016.

[13]. Hassan M. H. Mustafa, and Fadhel Ben Tourkia "On Comparative Analysis and Evaluation Of Social Insect Colonies' Behavior During Exploring Food Sources and Their Migration to A New Nest Versus Two of Neural Networks' Learning Paradigms. (Tandem Running Approach)" Published Journal IJATTMAS volume III issue XI. Nov. 2017 Page 33-41.

[14]. Hassan M. H. Mustafa, Fadhel Ben Tourkia. "On Application of Neural Networks' Modeling for Analytical Comparative Study between Two Optimally Selected Made Decisions by Ant Colony Systems". American Journal of Educational Research. 2018; 6(4):308-318. doi: 10.12691/education-6-4-3.

[15]. Zhang , K. , Genzburg ,I. and Sejnowski,T.J. , 1998 "Interpreting neuronal population activity by reconstruction" Journal of Neurophysiology, 79:1017-44,1998.

[16]. Zhang, Iris Ginzburg, Bruce L. Mcnaughton, and Terrence J. Sejnowski "Interpreting Neuronal Population Activity by Reconstruction: Unified Framework With Application to Hippocampal Place Cells". Downloaded from http://jn. physiology.org/ by 10.220.33.3 on October 29, 2016.

[17]. Singer et al. (2013) "Hippocampus: Remembering the Choices" published at Neuron. Mar 20, 2013; 77(6): 999-1001.Available Online-at: http://www.researchgate.net/publication/236073863 Hippocampus remembering the choices

[18]. Kraus BJ ${ }^{1}$, Robinson RJ 2nd, White JA, Eichenbaum H, Hasselmo ME "Hippocampal "time cells": time versus path integration". Neuron. 2013 Jun 19;78(6):1090-101. doi: 10.1016/j.neuron.2013.04.015. E pub 2013 May 23. Available online at http://www.ncbi.nlm.nih.gov/pubmed/23707613

[19]. Howard Eichenbaum "Hippocampus: Remembering the Choices" Neuron, Volume 77, Issue 6, p999-1001, 20 March 2013.

[20]. Sejnowski,T.J ,1999:Neural pulse coding" foreword article for (Pulsed neural networks), MIT press, 1999, pp 13-23. 
[21]. Wilson, M. A. and McNaughton, B. L., Dynamics of the hippocampal ensemble code for space. Science. 1993 Aug 20; 261(5124):1055-8. Available online at http://www.ncbi.nlm.nih.gov/pubmed/8351520

[22]. Fukaya, M., et al. Two level Neural Networks: Learning by Interaction with Environment, 1st ICNN, San Diego, 1988.

[23]. Yunlong Liu and Hiroki Yokota " Artificial ants deposit pheromone to search for regulatory DNA elements".Available online at: https://bmcgenomics.biomedcentral.com/articles/10.1186/1471-2164-7221.Published: 30 August 2006.The-image-available-online-at: :http://media.springernature.com/full/springer-static/image/art:10.1186/1471-2164-7221/MediaObjects/12864_2006_Article_604_Fig1_HTML.jpg

[24]. S. Goss, R. Beckers,J. L. Deneubourg, S. Aron, J. M. Pasteels " How Trail Laying and Trail Following can Solve Foraging Problems For Ant Colonies" Behavioral Mechanisms of Food Selection pp 661-678. NATO AS! Series, Vol. G 20 Behavioural Mechanisms of Food Selection Edited by R. N. Hughes (c) Springer-Verlag Berlin Heidelberg 1990. Available online at: https://link.springer.com/content/pdf/10.1007/978-3-64275118-9_32.pdf

[25]. Wilson EO (1971). The insect societies. Harvard University Press, Cambridge Massachussets

[26]. Simon Garnier, Maud Combe, Christian Jost, and Guy Theraulaz "Do Ants Need to Estimate the Geometrical Properties of Trail Bifurcations to Find an Efficient Route? A Swarm Robotics Test Bed". Published: on March 28, 2013.

[27]. Deneubourg JL, Aron S, Goss S, Pasteeis JM. (1989a) The self-organizing exploratory pattern of the Argentine ant. J Ins Behav in press.

[28]. Sasaki, Bert Hölldobler, Jocelyn G. Millar, Stephen C. Pratt "A context-dependent alarm signal in the ant Temnothorax rugatulus" . . .Pubished at the Journal of Experimental Biology 2014 217: 32293236; doi: 10.1242/jeb.106849.-Available-online-at: http://jeb.biologists.org/content/217/18/3229 .

[29]. Blum, M. S. (1969). Alarm pheromones. Annu. Rev. Entomol. 14, 57-80.

[30]. Blum, M. S. (1985). Alarm pheromones. In Comprehensive Insect Physiology, Biochemistry and Pharmacology: Behaviour, Vol. 9 (ed. G. A. Kerkut and L. I. Gilbert), pp. 193-224. New York, NY: Pergamon Press.

[31]. Crewe, R. M. and Fletcher, D. (1974). Ponerine ant secretions: the mandibular gland secretion of Paltothyreus tarsatus Fabr. J. Entomol. Soc. South Africa 37, 291-298.

[32]. Pratt S.C. (2010) Nest Site Choice in Social Insects. In: Breed M.D. and Moore J., (eds.) Encyclopedia of Animal Behavior, volume 2, pp. 534-540 Oxford: Academic Press. Available online at: http://www.elsevier.com/locate/permissionusematerial

[33]. Pavlov, I.P. Conditional Reflex, An Investigation of The Psychological Activity of the Cerebral Cortex, New York, Oxford University press, 1927.

[34]. Hampson, S.E. Connectionistic Problem Solving, Computational Aspects of Biological Learning, Berlin, Birkhouser, 1990. 
Hassan M. H. Mustafa, Fadhel Ben Tourkia; On Comparative Study for Two Selective Ant Colony's Optimal Decisions Versus Reconstruction Problem Solving by a Mouse Inside Figure of Eight (8) Maze. Transactions on Machine Learning and Artificial I ntelligence, Volume 6 No 3 J une (2018); pp: 1-19

[35]. Thorndike E.L. Animal Intelligence, Darien, Ct. Hafner, 1911.

[36]. Hassan H. and Watany M. On Mathematical Analysis of Pavlovian Conditioning Learning Process using Artificial Neural Network Model, 10th Mediterranean Electro technical Conf., May 29-31, 2000, Cyprus.

[37]. H. M. Hassan, and M. Watany. "On Comparative Evaluation And Analogy for Pavlovian and Throndikian Psycho-Learning Experimental Processes Using Bioinformatics Modeling", published at AUEJ, 6,3, 424432, July. 2003.

[38]. Hassan, M.H., 2008 " A Comparative Analogy of Quantified Learning Creativity in Humans Versus Behavioral Learning Performance in Animals: Cats, Dogs, Ants, and Rats.(A Conceptual Overview), published at WSSEC08 conference held on 18-22 August 2008, Derry, Northern Ireland.

[39]. H.M. Hassan, "On Mathematical Modeling of Cooperative E-Learning Performance During Face to Face Tutoring Sessions (Ant Colony System Approach)"published at IEEE EDUCON 2011,on Education Engineering-Learning Environments and Ecosystems in Engineering Education, held on April 4-6, 2011,Amman, Jordan. Available on line at: http://www.google.com.sa/url?sa=t\&rct=j\&q=\&esrc=s\&frm=1\&source=web\&cd=9\&ved=0CHQQFjA/\&url =http\%3A\%2F\%2Feditlib.org\%2Fd\%2F45687\&ei=rsUFU66SAccOWWakIHAAQ\&usg=AFQjCNFXdog2WcQE 3DE5-8sVp7aaVH4LW

[40]. H. M. Hassan. “On Learning Performance Evaluation for Some Psycho-Learning Experimental Work versus an Optimal Swarm Intelligent System.", Published at ISSPIT 2005 (18-20 Dec.2005). http://ieeexplore.ieee.org/xpl/login.jsp?tp=\&arnumber=1577175\&url=http\%3A\%2F\%2Fieeexplore.ieee. org\%2Fxpls\%2Fabs all.jsp\%3Farnumber\%3D1577175

[41]. H.M. Mustafa "A tutorial titled: Building up bridges for natural inspired computational models across behavioral brain functional phenomena; and open learning systems", that has been presented at the International Conference on Digital Information and Communication Technology and its Applications

(DICTAP 2011) held at Universite de Bourgogne, Dijon, France. (June 21-23, 2011). Available online at: http://dictap2011.sdiwc.us/tutorials.php

[42]. Hassan M. H. Mustafa, and Fadhel Ben Tourkia "On Analysis and Evaluation of Learning Creativity Quantification via Naturally Neural Networks' Simulation and Realistic Modeling of Swarm Intelligence" published at the proceeding of the conference Eminent Association of Researchers in Engineering \& Technology(EARET).To be held on 8-9 January 2018.

[43]. Hassan M. H., et.al"On Comparative Analogy between Ant Colony Systems and Neural Networks Considering Behavioural Learning Performance" Journal of Computer Sciences and Applications, 2015, Vol. 3, No. 3, 79-89 Available online at http://pubs.sciepub.com/jcsa/3/3/4 @ Science and Education Publishing DOI:10.12691/jcsa-3-3-4.

[44]. Hassan M. H. "Analytical Comparison of Swarm Intelligence Optimization versus Behavioral Learning Concepts Adopted by Neural Networks (An Overview) American Journal of Educational Researchhttp://pubs.sciepub.com/education/3/7/2/index.html Vol. 3, No. 7, 2015, pp 800-806. doi: 0.12691/education-3-7-2 
[45]. Hassan M. H., et.al "Comparative Performance Analysis and Evaluation for One Selected Behavioral Learning System versus an Ant Colony Optimization System" Published at the Proceedings of the Second International Conference on Electrical, Electronics, Computer Engineering and their Applications (EECEA2015), Manila, Philippines, on Feb. 12-14, 2015.

[46]. Hassan M. H., et.al. "On Assessment of Brain Function Adaptability in Open Learning Systems Using Neural Networks Modeling (Cognitive Styles Approach). Journal of American Science 2011; 7(9): 238-247]. (ISSN: 1545-1003). http://www.americanscience.org 